\section{The Death of the Desk Crit}

Malini Srivastava

University of Minnesota

\section{John Barton}

Stanford University

\section{Mike Christenson}

University of Minnesota

\section{ABSTRACT}

This paper describes three alternative architectural studio teaching models taught by the authors at the University of Minnesota and at Stanford University. The three models attempt to build independent and collaborative capacity in students and to emphasize iterative components of the design process. Collectively, the models reflect the authors' shared conviction that studio education is quite pliable and available to a wide variety of changes in approach and methods.

The three models discussed in this paper are the Harkness model, the Exchanges in the Thick Middle and Shifting Allegiances. The Harkness model was implemented and tested in early undergraduate studios at Stanford University. Exchanges in the Thick Middle and the Shifting Allegiances studios, studio pedagogy based in play frameworks of "movement, change, alternation, succession, association and separations" (Srivastava and Christenson 2018), have been tested at the University of Minnesota and North Dakota State University in both undergraduate and graduate studios. All three models are briefly introduced in this paper, followed by a description of the typical day and a typical review in the studios. The conclusions section briefly outlines the overlaps and differences in the three models.

\section{THE HARKNESS MODEL}

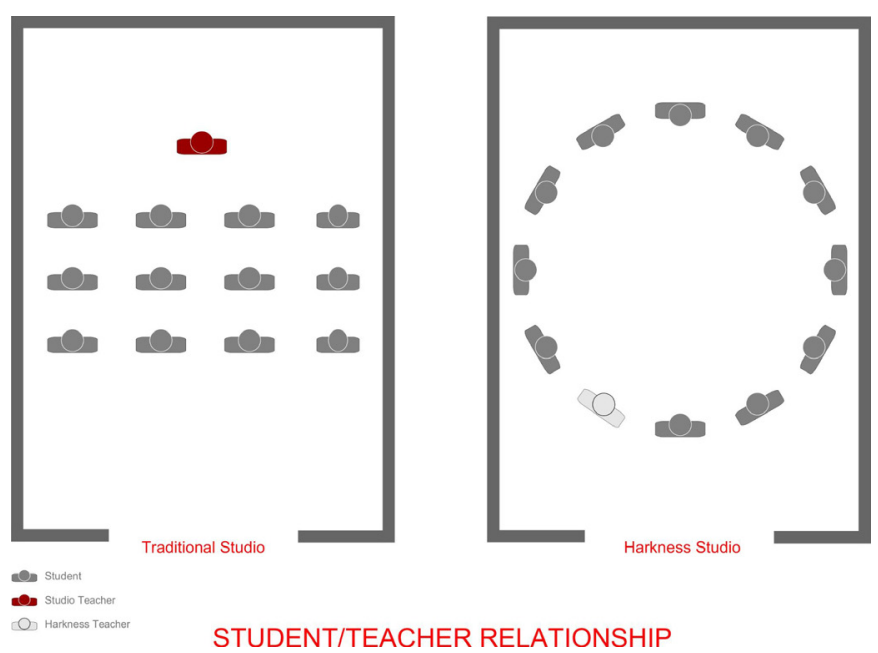

Figure 1. Traditional studio (left) and Harkness studio (right).

The Harkness model is a discussion-based collaborative learning environment with a largely silent teacher. Harkness was developed at the Phillips Exeter Academy (Exeter), and though anecdotally deemed successful, has not been widely disseminated or studied.

Harkness has several key components. Most importantly, it is student-driven in small class sizes (usually 12 students) around a table where each person can see all others (Williams, 2014). At its core, Harkness is based on collaborative inquiry. It places high value on student preparation, discussion, and discovery and low value on instructor authority (Williams, 2014, Smith et al 2009). It builds an individual's sense of responsibility for his own education (Smith et al, 2009). In Harkness the goal of education is not the acquisition of facts; rather it is the development of cognitive skills that allow for 
independent and supportable positions from disparate points.

The role of the teacher in Harkness is unique. The "teachers serve as guides, questioners, facilitators and resources, never lecturers, interrogators, or taskmasters" (Courchesne, 2005). And, "the discussion does not belong to [teachers]" (Williams, 2014). The discussion - its beginning, structure, and form - belongs to the students. An experienced Harkness teacher will begin class from a neutral prompt like "Where shall we start today?" "The key issue is encapsulated in the questions "'Who is asking the questions?' and 'Who is answering the questions?"' (Vorkink, 2015). In Harkness the students do both.

Many architects, used to a loquacious studio master, will be suspect of instructor silence. But, while the instructor may not participate in the conversation, her contribution precedes the discussion through the carefully delineated assignments.

Students prepare by reading/doing the assignments. But more importantly they must come with questions and an open mind. The assignments are not designed to deliver correct answers but rather to prompt a discussion that hugs ambiguity. Thus the student should not prepare to be right but to share insights and adjust his views.

\section{EXCHANGES IN THE THICK MIDDLE}

The second approach, Exchanges in the Thick Middle, seeks to minimize the traditional linear quality of architectural design pedagogy. The approach aims at removing the "beginnings" and "endings" of design processes, characterizing them instead as cyclical exchanges between the highly specific and the highly fluid. In many traditional approaches, design pedagogy tends to move conditions from disordered to ordered, or from fluid to fixed, or from large-scale to smallscale. In the pedagogy of the Thick Middle, architectural design processes are emphasized as capable of cycling between different kinds of order, different forms of order, different scales of order, or different degrees of order. Thus, design operates without obviously increasing or decreasing the order of found conditions: it is positioned as an act of re-organizing rather than an act of resolving. Project reviews serve a distinct purpose in this pedagogy. Traditional juried reviews are not conducted. Instead, the review becomes an opportunity to place material in front of an audience in a way which invites the audience to creatively respond to the work. The creative response is embodied in the tactic of project exchange, in which each student assumes ownership of another student's project; the new project thus becomes their responsibility to develop - until the next exchange. In this way, the "beginning" and "ending" of the project are blurred, and what emerges instead is a continuous process of iteration and negotiation, in which conflicting viewpoints are brought to bear on a never-fully-settled body of material.

\section{SHIFTING ALLEGIANCES AND SHARED AUTHORSHIP}

The third approach, Shifting Allegiances/Shared Authorship, asks the students to consider all the work produced in the studio as being held in shared authorship. The studio cycles between individual development of artifacts, sharing and presenting the artifacts in all-studio group discussions, grouping and categorization of the work represented by the artifacts (Srivastava 2019). This process of distributing the work into discrete categories agreed upon by the studio, develops common terminology to recognize and identify the artifacts into thematic categories and identify new work groups and collaborations. In Figure 2, each circle could be read as artifacts contributed by the students or could be read as the students themselves. Of note is the concept, that students select and develop any of the emerging themes as their focus until the next cycle, marking a milestone event where allegiances to projects or groups might shift. The studio privileges any prior development of the theme as existing context for the student(s) inheriting or choosing to move forward with any of the shared work.

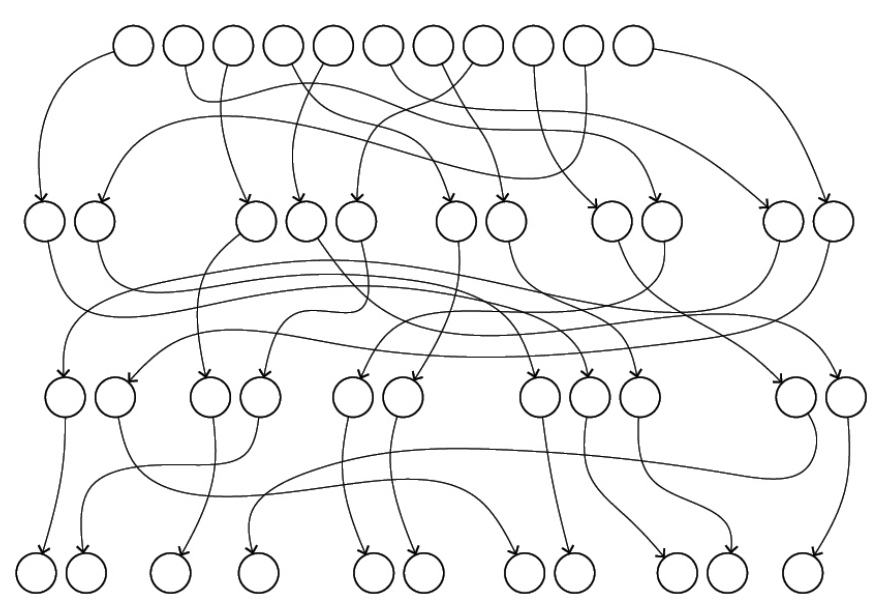

Figure 2. Sharing artifacts, categorizing the work and people based on thematic categories. (From top: Sharing/Discussion; Sharing, Discussion and Identification of thematic categories and new work groups; Sharing, Discussion and Identification of thematic categories and new work groups; Sharing, Discussion.)

While the learning objectives, milestones, and core competencies and pre-determined and provided by the instructor at the beginning, the week-to-week specifics are determined through large-group studio discussion and shaped by the emerging thematic ideas. Although the instructor participates in the small group discussions, in large group discussions where all the work of the studio is being categorized and thematic ideas are being identified, the students lead the discussions and make final decisions about thematic categories, work groups, schedules and plans. As such, at any given time, one or more students self-organize into sub-groups around particular themes of interest. These sub-groups shift allegiances or reorganize at the milestone all-studio discussion and sharing events: some students choose to stay with a thematic idea that they were working on, while others choose to advance thematic ideas that had been previously developed by others. While the instructor asks the students to have individual authorship of artifacts for the purpose of meeting the learning objectives and assessments, the students in the sub-groups determine the research, artifacts, and tools that need to be grouped in order to develop the concept and educate each other in the studio. 


\section{A TYPICAL STUDIO DAY: HARKNESS}

A typical day has two formats: full class discussion or work periods punctuated by large or small group discussions.

The mechanics of the full class discussion are simple; it is a good replacement for lectures. Assign a list of readings, exercises, etc. that illuminate the topic. The material should leave room for interpretation. Assemble at the table and begin with a neutral prompt like "Where shall we begin?" Limit yourself to active listening.

Expect there will be silences. This is normal but very difficult for new Harkness teachers. Wait them out. It will not take long to become comfortable with silence and that comfort will accrue to the students as well.

The discussion will likely not go where you thought it would go. The conversation may take wild turns or be wholly unexpected. Have patience and trust that the students are working through the material their way.

Finally expect to learn something. As the students grapple with the material they will come at it from new directions that you are not familiar with. Learn from this and become a student with them.

The work/small group discussion is a good proxy for the desk-crit. Bring everyone to the table with their drawings and models and give a short graphic exercise; examples may include:

-draw two diagrams of your scheme

-draw three new schemes

-diagram/cartoon your final presentation.

Once the exercise is complete ask the students to form small groups and have them share their work, get comments and ask questions. Move about the room and listen to the conversations but do not participate. Once the conversation has exhausted itself bring them back to the table to begin the cycle again with another short exercise. Close the session with a large group discussion.

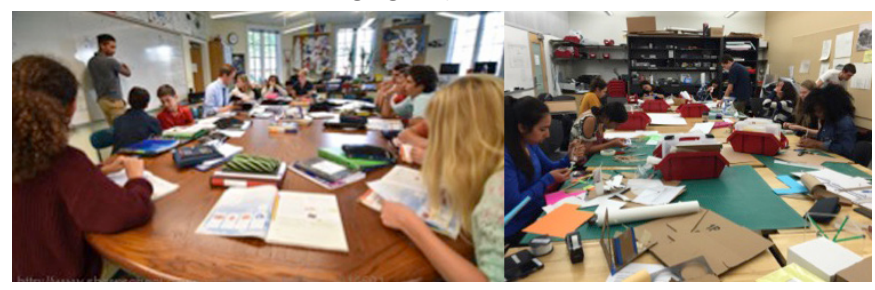

Figure 3. Harkness model.

This is a powerful tool to develop comfort with the ambiguity of iteration. The conversations themselves will be short but intense. Students will be remarkably honest about their struggles. Capturing the honesty and inquiry with follow-up exercises is crucial.

\section{A TYPICAL STUDIO DAY: THE THICK MIDDLE}

In this studio, a typical day begins with a brief meeting of all students and the instructor, with a threefold purpose. The first purpose (the least critical pedagogically) is to address any informational needs or schedule impacts. The second purpose - to define a working plan for the day - is important to the extent that it organizes students into daily working or discussion groups. The third purpose - that is, the opportunity for students to meet in a large group to discuss questions - is the most important pedagogically. Questions that emerge in this part of the meeting can range from the practical to the political (such as questions about why the studio brief is structured in a particular way). Discussions can become intense or even contentious, so it is important that all participants are cognizant of time limits: the meeting does not usually extend more than fifteen or twenty minutes. Apart from limits on time, the instructor enforces only one other criterion for questions: that they should emerge from the work. As an example, a student who seeks to challenge a particular requirement of the brief cannot do so without demonstrating, through their work, that they have considered the implications of the challenge.

Next, the instructor meets with each of several small groups in turn. Students can and should move between groups from one day to the next: in this way, they begin to uniquely develop an understanding of each of their colleagues' work that will enable them to assume ownership of it at some future time. Either the students take turns informally presenting their work-in-progress to other students in the group, or the projects are considered one at a time in the absence of verbal comments by the owner of the work. That the meetings are structured as small-group discussions rather than as individual desk crits or individual table meetings is critical to the pedagogy. A characteristic of individual, instructor-led meetings is that the instructor assumes the position of authority and the ability to pronounce on the validity of student design moves. While this model may be useful in reinforcing traditional master-apprentice hierarchies and in establishing a canon of acceptable interpretive criteria, it is not productive in opening up alternative readings, particularly if these alternative readings threaten to call the assumptions of the brief into question. It is precisely in this spirit that emphasizing to the students that the studio brief itself is a designed artifact, capable of sustaining change and refinement, can go far towards improving students' productive and convinced engagement with the studio.

Finally, at the end of the studio day, the students are once again called together into an all-group meeting, following the same agenda as the beginning-of-studio meeting, but with the added expectation that students will voice any issues that arose directly as a result of their group work during the day. Thus, the value of small-group meetings can be shared with the group as a whole, and the instructor need not summarize the day's work. The end-of-studio meeting also serves as a useful "bookend" on what would otherwise be unstructured work time; by requiring all students to be present at the beginning and end of studio, though not necessarily in the middle, students gain a degree of control over their use of studio time even as the importance of the group discussion is emphasized. 


\section{A TYPICAL STUDIO DAY: SHIFTING ALLEGIANCES}

The majority of in-studio time is spent in discussion in small and large groups rather than at desks. As such, the studio requires space for the studio to meet as a large group while displaying the work. The studio starts and ends with an all-group discussion.

In Figure 4, the daily studio structures are outlined. The left side of the diagram is the beginning of the studio period and the right side of the diagram is the end of the studio period. The black circle in this diagram is the instructor and the white circles are the students. With rare exceptions, the studio day starts and ends with a large group meeting where instructor and students are equal participants.

At the beginning of studio, four questions or discussion items are repeated on most days. First, announcements regarding logistics and schedules are made by the instructor and various students; second, any problems or roadblocks encountered are discussed; third, each student shares what they have worked on and an issue that is the focus of their study; and lastly, based on the three previous items, a plan for the day is discussed. The beginning-of-day all -group discussion closes with a schedule, list or plan for the day.

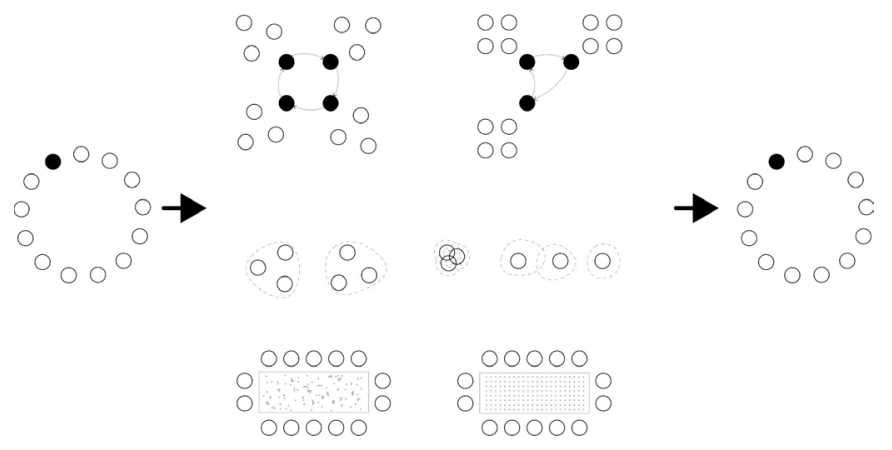

Figure 4. A typical day in the Shifting Allegiances Studio.

The plan for the studio period typically alternates between small group discussions, work days interspersed with short, small group discussions or long large group display and discussion. This is the middle section of Figure 4, with the instructor joining small group discussions as an active participant and large group discussion and work groups as an observer. For both the small group discussion and large group discussions, the two key questions are a definition of the thematic concept that is emerging in the work and a clear plan of what work needs to be done next based on identification of question or thematic idea. This includes deciding what needs to be researched, analyzed, made and the work partnerships and individual efforts needed to accomplish tasks at hand. Discussions incorporate comparisons and critique of work and consideration of tools and competencies needed, shared, learned and taught in order to meet the studio's collective learning goals outlined by the instructor. Sometimes the studio day is spent as a work day by the students working in various permutations (center of Figure 4). Dashed lines show the projects while the outlined white circles are the students. For example based on common thematic interests, the students might band together to do a project, or they might work on individual projects but share the research work and various other combinations. Ideally the evolving cooperative structures would be based on the needs of the studio and thematic interest overlaps.

At the end of the studio, the large group gathers again to quickly share the thematic concepts being investigated and what they are making. Key points to share are (a) observing, reading, articulating the thematic concepts emerging in the studio and combining work generated by various people to strengthen emerging themes; (b) what is being made, researched or tested in order to advance concepts, and by whom, and (c) invariably discussions of problems the students are encountering are resolved by creating cooperative structures that allowed for peer-learning and teaching.

\section{REVIEW DAY: HARKNESS}

The traditional final jury is fraught. It is angst inducing for students, questionable educationally and dubious as a model of practice (Anthony, 1987). A Harkness instructor will find a return to the classic studio model disastrous. Thus the Harkness final review must be carefully crafted.

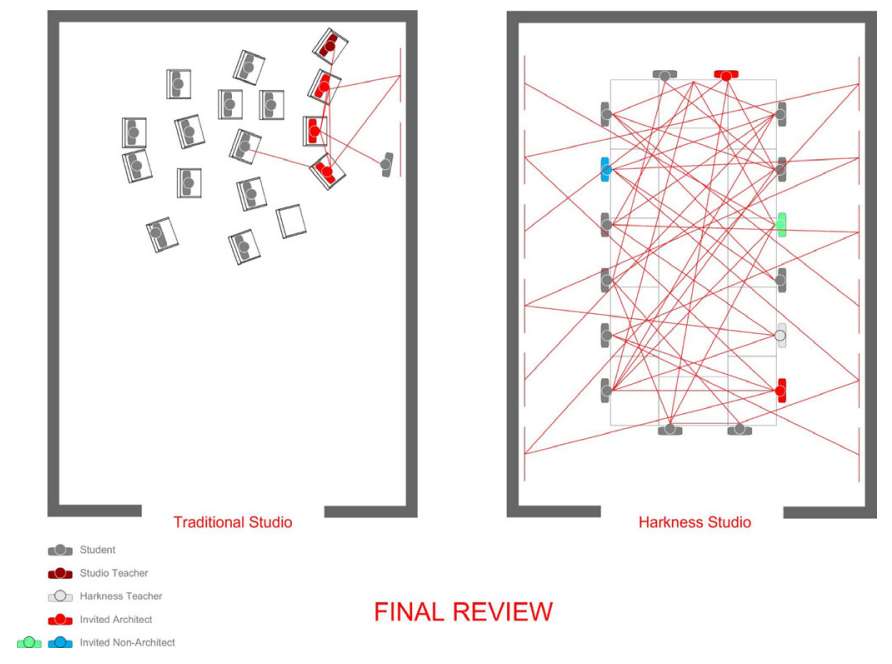

Figure 5. Review day: Harkness model.

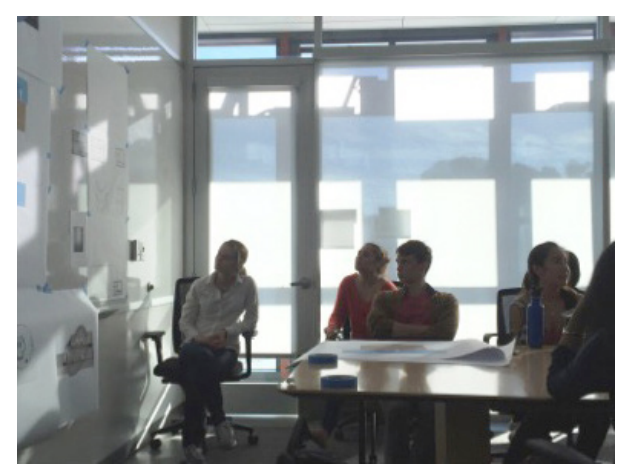

Figure 6. Review day: Harkness model.

Let the students determine the mode of the review (invited guests, large group, or small group). They own the classroom so they decide. 
Meet with any invited jurors in advance. The guests must understand that they are invited to a conversation not a commentary session. Further, rational people may become unpleasant in a review and a boorish guest will undermine the conversation.

Pin up the drawings around the table. Have all parties introduce themselves and then ask the students how they would like to proceed.

In most cases the class will choose short presentations by all the students followed by a conversation. The conversation will privilege process over product. References to drawings and models will be comparatively few. The conversation will be relaxed, process heavy and fault light. The students will point out what they could have done better and will sketch improvements. More importantly, they will cogently comment on each-others' processes and schemes.

Expect a mix of irritation, awe and joy from the jury. They may relapse into a top-down criticism of the drawings. If necessary call a break and speak to these jurors. The depth of the conversation and the strength with which the students display their design processes may also awe them. If the jurors are willing to give themselves over to this process, they will join a true conversation about architecture.

\section{REVIEW DAY: THE THICK MIDDLE}

The reviews in the Thick Middle studio follow one of several formats geared towards placing the work (drawings and models) at the center of the discussion in support of a common pedagogical goal, namely the project exchange. A typical approach is to structure the review as a series of simultaneous, informal conversations between students and invited guests, as a result of which students negotiate and agree between themselves on how to exchange projects with each other. As with the Harkness model, process is emphasized; while certain deliverables may be required of the students (e. g., floor plans at a fixed scale), there are no limits on the extent or form of the work exhibited at the review.

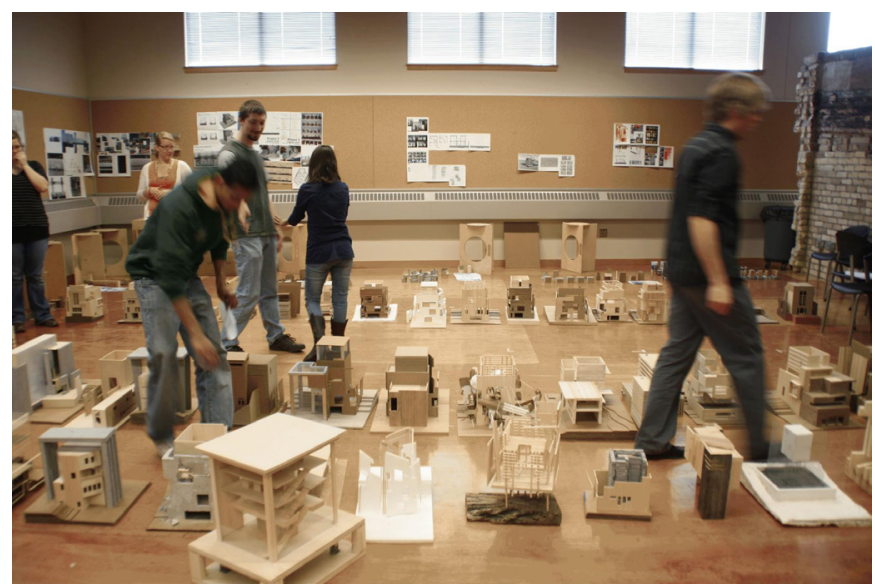

Figure 7. Review day: Thick Middle Studio.

As a rule, practicing professionals tend to make good invited guests because they can testify to the application of a "project exchange" model within architectural practice, i. e., that it is normal practice rather than an exceptional occurrence.

\section{REVIEW DAY: SHIFTING ALLEGIANCES}

As with the Thick Middle pedagogy, external reviewers add new voices to the large-group discussions. Typically, the students design the structure and schedule of the review with the instructor's participation. The reviews can be structured in multiple ways, including an exhibit style review, where half the students and reviewers circle between various groupings of work arranged by concepts or issues being pursued.
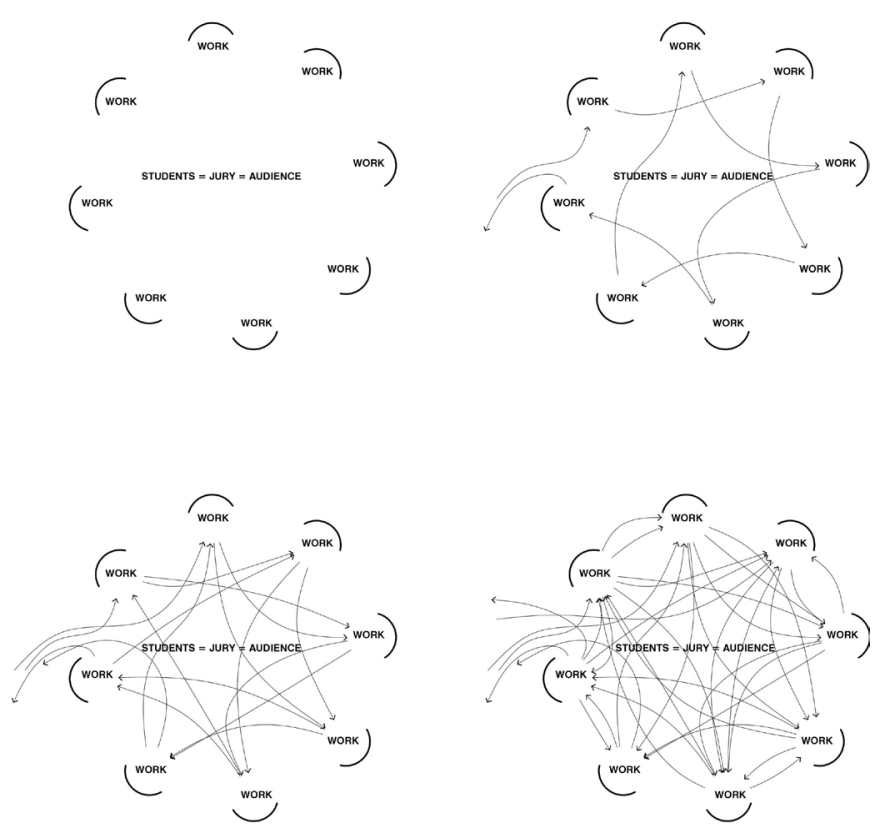

Figure 8. Review day: Shifting Allegiances Studio.

Multiple students in various permutations and combinations present the works arranged in groupings. The focus of discussion at the review is on negotiating various readings of the work and its potential for future development rather than the authorship behind the work. Students typically present a question or issue that they are researching or studying, referencing the work produced. Discussion is led and moderated by the students in their small groups. These small discussions occur simultaneously and each concept or issue may be discussed multiple times during the duration of the review. In this type of review the instructor and the students invite the guests into the review. Therefore, multiple guests which includes students from other studios will cycle through as the review progresses. This structure negates the need for a central authority or expertise whose opinion, reading of the work or feedback needs to be heard by the entire studio for the entire duration of the studio. In a distributed review of this kind, the studio will typically gather back together in the last hour of the review to recap for the class, the discussions that they had with various reviewers. It allows student groups to edit and decide what is important to share with the large studio group as a whole. 


\section{CONCLUSIONS}

In support of their shared goals of improving independent and collaborative capacity and emphasizing iterative components of the design process, the three models share some structural similarities. For example, all three models bypass the traditional presenter-jury-silent audience layout, replacing it with a group discussion where the students, instructor, and external reviewers participate equally and students lead the discussion around thematic ideas, referencing not just their own projects but the work of others, and of the studio as a whole. Though reviewers bring expertise and new points of view to the discussion, theirs is not the only voice heard. Instead of enabling a silent, uninterested, background audience, all students are expected to be actively engaged throughout the review.

The three models address the studio's spatial configuration in a similar spirit: due to the substitution of group discussion for traditional desk crits, the studio needs to accommodate the continuous and highly present display of work-in-progress: the emphasis is on a shared effort rather than individual artifacts that disappear in piles on individual students' desks. The need for discussion space suited to small-group discussion and large-group discussion suggests that the students be spatially dispersed configured around a shared meeting, pin-up, and display space such that any discussion (and the work under discussion) is available to all of the students at any given time.

In addition to structural similarities, the three models share the expectation that students will teach each other, whether through student-led discussion or through the negotiation necessary to exchange projects or to develop allegiances.

In the case of the two models that expect a degree of shared or collaborative ownership of projects - specifically the Thick Middle and Shifting Allegiances models - assessment is done on a per-artifact basis: each artifact related to a project, such as a drawing or a model, is credited to the student who created it, irrespective of the ultimate origin of the argument or idea being tested in the artifact. Students submit whatever artifacts that they have authored themselves to a shared drive on a regular schedule (usually weekly).

Studios based on each of the three models are currently taught at different levels at two different universities. The Harkness studio is focused on cohorts of students who may be either Architecture or non-Architecture majors and is offered as a first Architecture Foundation Design studio. The Shifting Allegiance studio is taught at the graduate level during the final or penultimate year before graduation, where literature research and competency development with advanced measurement tools (such as parametric energy modeling) are intrinsic parts of the coursework. The Thick Middle studio operates convincingly at the undergraduate level but with some difficulties at the graduate level, where individual competency and individual research focus are, for curricular reasons, expected to take on an increasingly central role.

The instructors responsible for designing and implementing the pedagogies discussed here are working toward sharing of curricular approaches. We see our future work as simultaneously concerned with looking backwards and forwards. Backwards, in this case, means deepening and broadening the theoretical basis for all three approaches, at least in part aimed at differentiating the pedagogies from each other and from established approaches. Looking forward means identifying teachers and researchers who share our dissatisfaction with the existing situation and who are willing to consider and test alternatives.

\section{Notes}

1. Anthony, K. H. (1987). Private reactions to public criticism; students, faculty, and practicing architects state their views on design juries in architectural education. Journal of Architectural Education, 40(3), 2-11.

2. Srivastava, M., \& and Christenson, M. (2018). "Play in Architectural Pedagogy: Shifting Allegiances and Trading Projects," presented at PLAY with the Rules (2018 Fall Conference of the Association of Collegiate Schools of Architecture).

3. Srivastava, M. (2019). "From Problem to Net Positive: The transformation of existing, inefficient building stock." IN PRESS, 2019 Reynold's Symposium: Education by Design, 2019.

4. Courchesne, C. G. (2005). "A suggestion of a fundamental nature": Imagining a legal education of solely electives taught as discussions. Rutgers L.Rec., 29, 21-21.

5. Smith, L. A., \& Foley, M. (2009). Partners in a human enterprise: Harkness teaching in the history classroom. The History Teacher, 477-496.

6. Vorkink, P. (2015). Gnothi Seauton: Why and How to Tech Religion and Philosophy to Secondary School Students. Unpublished doctoral dissertation, Harvard University, Cambridge, MA. Courtesy of the author.

7. Williams, G. (2014). Harkness learning: Principles of a radical American pedagogy. Journal of Pedagogic Development, 